\title{
EDITORIAL
}

\section{Then and Now}

IT was an exciting adventure to have been in at the beginning of a new specialty in medicine, as I was privileged to be in the matter of caring for patients with spinal cord injuries. Extending beyond the field of medicine itself, it was a new epistemological experience. One learned and observed others learning, and saw knowledge painfully acquired and accumulated. Unhappily, one also encountered the difficulty of extending this knowledge beyond the small circle of those immediately concerned, and the apathy with which early, and even later, efforts to do this were greeted.

Somehow, over the years, interest grew, due in large part to activity outside the medical community. Stories of successful rehabilitation had great public appeal and were popular in all the media. Sports for the handicapped played no small part in this-another achievement of our late great colleague Sir Ludwig Guttmann. Television in particular made the processes and results of rehabilitatory efforts familiar to huge publics which, a few years before, had never heard the words paraplegia and quadriplegia. In this there was unquestionably an element of exploitation; popular reports of medical advances in general, often with more emphasis on the sensational than on accuracy, carry the risk of raising false hopes, overlooking difficulties and encouraging premature claims. On balance, however, publicity about spinal cord injury has surely done more good than harm.

During the same period, as the so-called pioneers became less active, a new generation of devoted and enthusiastic workers took the field, encouraged by increasing awareness of their work, more sophisticated technological equipment and, by one means or another, improved funding. With this, however, they must now be expected to assume new burdens of responsibility, and to be conscious always of two particular obligations. First, in their enthusiasm to investigate and publish, they must take care not to waste their resources on repetition. It has been disconcerting to observe, among some reports appearing in recent years, a lack of familiarity with what has been done before. Not only in this journal, but scattered through the literature there is a considerable body of knowledge which is still relevant and still a good basis for present and future studies.

Another concern is that the men and women in this work should not lose what I dare to call the living human touch, which is at some risk as an enterprise increases in scope and in the numbers of people involved. The friendly intimate physicianpatient relationship which most of us enjoyed in the period after World War II might have arisen, at least in part, from our having served in the armed forces along with those we were treating. It continued, possibly, because there were long-term patients and the physicians were full-time staff members of publicly funded hospitals. Beyond this, I like to believe, the old sense of a doctor's primary responsibility to each individual patient was still a major influence on what happened between them. There is no reason why that should not still be the case, and every reason to hope anxiously that it may be.

And, as with patients so with colleagues, we may hope that the sense of fellowship that marked our relationships during the early days of the International 
Medical Society of Paraplegia may not fade. For all that it has earned and achieved wider recognition, ours is still a relatively limited field and our numbers are still not so great as to be unwieldy. It is devoutly to be wished that we may continue to be bound together by our common concerns, and that at least one international group may show, as I used to say at our annual meetings, that there are more things that draw people together than drive them apart.

\section{Herbert S. TALbot, M.D.} Boston, U.S.A.

\section{Note from the Editor}

Unfortunately, owing to a change in Printers of PARAPLEGIA, there is a delay in publishing some of the papers from the 198I Meeting of the International Medical Society of PARAPLEGIA at Stoke Mandeville, Aylesbury, England. 